\title{
RETURNING HOME FROM IRAQ
}

It's not easy to come home from war. Even if you're lucky enough to have survived mentally and physically, you still have to get used to the fact that most Americans can't relate to where you've been, what you think, what you've seen, how you feel, and what you've done.

I should know. I spent parts of three years as a journalist in U.S.occupied Iraq, in Baghdad, Fallujah, Najaf, and other locales that have become more known for their battles, kidnappings, and car bombs than for their historic architecture, culture, or people. I existed in an atmosphere where I couldn't walk down the street, go to the grocery store, or eat in a restaurant without seriously considering the security situation. Explosions and gunfire were parts of my daily life. I saw the smelly, dirty remains of dead Iraqis before my eyes.

All the things that most Americans take for granted, like clean water and consistent electricity, were unavailable. No gym memberships. No sporting events. No hanging out at the neighborhood bar. No hiking or fishing or bowling. Just work, and the belief that by being there and reporting the news I was making some kind of difference.

As a journalist, I considered myself safer than most men and women who served in the military. I was in Iraq as an observer, interviewing 
regular people about their daily lives. This was something most Iraqis appreciated, and while there was always the chance that I would be killed or injured while caught in the cross fire, no one was targeting me directly and I was never ordered to shoot anyone myself.

I traveled in old, beat-up economy cars and station wagons that blended into the day-to-day of regular Iraqi life. Iraqi hospitality is legendary. So, despite war going on all around, wherever I went to conduct interviews, I was met with tea and snacks and often a complete lunch. Since I didn't carry a gun and presented myself as impartial, even most Iraqis who participated in attacks on American solders felt comfortable speaking and meeting with me. The work was dangerous, but more in the way that walking through a crime-ridden city at night is dangerous. I might get hurt, but I could also take precautions to keep myself relatively safe.

In April 2004, I was working west of Baghdad, interviewing Iraqis who had family in Fallujah, when I saw an American tank burst into flames on the highway, a dark red fire with black smoke spiraling toward the sky. More tanks sped past us and people shot at them. An ambulance rushed by, its sirens blaring. I ran toward a nearby mosque and hugged the wall to avoid the gunfire. Next to me stood a local sheik. When I told him I was a journalist, he told me his brother and sons were being held at Abu Ghraib. I took his mobile number and promised to call him to make an appointment later.

It was surreal. As I hugged the wall of the mosque, I met the head of a local relief agency who hold me about his charity's blood drive for civilian victims of the siege of Fallujah. He wanted to stay and talk, but I apologized and rushed back to my car. I sat in the old station wagon as my translator drove it through the back roads into Baghdad. It took an hour and a half to get home this way, but it was better than risking shrapnel from an exploding tank. 
Those kinds of experiences weren't easy for me. While I was still in Iraq, I cried at the slightest provocation. Every afternoon, after my time in the field, I would sit transcribing interviews with my translator, tears running down my cheeks. At night it was worse. The tragedy unfolding on the streets of Baghdad and Fallujah began to invade my dreams.

In one recurring nightmare, I found myself at a bus depot in downtown Baghdad unable to get a ticket to Istanbul. From Istanbul, I would have been able to fly home to California. "I need to get to Istanbul," I would say with great urgency to a myriad of conductors, concessionaires, and drivers, but every time I would be denied.

"There are no buses to Istanbul," a conductor would say as a large I970s superliner pulled out with ISTANBUL emblazoned on its front. When I ran to the driver of the bus, he turned to me. "All sold out," he would shrug. This would go on for some time until, eventually, a long-limbed man with a daffy smile and long tongue would approach me with a kitchen knife and cut off my head, in the style of the most macabre Hollywood slasher movie. Blood would spurt from the stump of my neck as my face looked on in horror. Finally, my translator Waseem would appear and wrestle the knife from my crazed assailant and I would wake.

I knew I had to get out of Iraq, especially after I went to Fallujah at the beginning of May 2004 and saw the aftermath of the U.S. siege there. In Fallujah, I watched as medical teams pulled the already decomposing remains of a middle-aged woman out of the ground before burying her in a makeshift cemetery in the municipal football stadium.

Back in Baghdad, I couldn't get her out of my mind. We had never met in life, but now that she was dead, she appeared to me as a vision over and over again. When I was awake, she hovered directly in front of my eyes with a kind of translucent quality. When 
I was asleep, she appeared whole in the ground. I drank more and worried I was developing post-traumatic stress disorder, a psychological disease that often strikes soldiers and others close to severe violence.

I thought of broken Vietnam veterans I'd met back home in the States. I knew I didn't want to end up like them, tortured for decades by my wartime experiences. Every person has a breaking point, and I could tell that I was reaching my limit. So I called my editors, said goodbye to my Iraqi friends, and took a bus from Baghdad to Kurdistan in northern Iraq. From there, I took a taxi and then a bus back to Ankara where I spent a week "cooling off" with friends in the cafés and restaurants of the Turkish capital. I walked the streets of Aksaray, an old section of Istanbul, and relaxed in the heat of a Turkish bath. Then, with the war at least a little bit out of my system, I boarded a plane to the States. A week later, I was in California sleeping next to my fiancée in the back of her parent's house.

But I wasn't really happy back at home. Her parents lived a few blocks away from the local ABC-TV station's news helicopter pad. Every time I heard the chopper go by, I felt agitated. I woke up in the middle of the night and paced through the house and into their backyard. I had visions, usually during the daytime, of people and things I had seen in Iraq.

I'd left Iraq, but Iraq did not leave me. I'd left Iraq, but I knew civilians who lived there could not. I felt like I'd abandoned my Iraqi friends, my translators and their families, by coming back to the United States. How could I return to California and experience the "comforts of home" when death and destruction continued overseas? I tried to call Iraqis I knew as often as possible, but it still didn't seem right. My head told me I should relax and enjoy life, but the rest of my body pulled me back toward the Middle East. 
My knees ached, but I couldn't figure out why. Perhaps it was from stress that had taken over my body. Perhaps it was weight I'd put on from too much drinking. I tried eating better and bicycling, but the pain wouldn't go away. I felt alone-I was surrounded by friends and family, but all of them saw the war in Iraq simply as a political debate-if they thought about it at all. How could they go on talking about such trivial things-iPods, celebrities, the latest fashionswhen there was A WAR GOING ON!?

"I found that the most difficult part of this experience in Iraq was coming home," my friend, filmmaker Andrew Berends, said in his director's commentary on the DVD of The Blood of My Brother. ${ }^{1}$ The award-winning documentary follows the family of a Shiite camerastore owner in Baghdad after he's killed by U.S. soldiers.

"The first two weeks back in New York were like a honeymoon," Andrew explained. "I was so happy. I was free. I was safe. I could walk around. But very quickly, I sunk into depression. I sent an e-mail to four or five other journalist friends I had in Iraq, all of whom happened to come back to New York the same month. I told them I couldn't sleep. I couldn't focus on my work. I felt depressed. I was having trouble in my relationship."

Andrew and I lived together during part of our time in Iraq and occasionally went out in the field reporting together. While we were together in Baghdad, I watched Andrew with a sort of envy. He was so calm, fearless. I was sure he was coping better than I was. When he saw an explosion or gunfire, he would get out of the car and stand silently, pointing his camera directly at the carnage, while I would avert my eyes and look for a safe place to stand until the fighting stopped and I could conduct interviews. Back at the hotel in the evening, Andrew would sit quietly listening to music on headphones for hours, before busting out with a wry comment that would cause the rest of us to erupt in laughter. 
In August 2004, Andrew covered the Shiite uprising in the holy city of Najaf. In one scene he filmed for The Blood of My Brother, the Iraqi police and military gun down dozens of peaceful demonstrators who'd come out to protest during a break in the battle. Civilians and fighters alike fall down dead, shot right in front of his camera.

"I remember feeling very calm [with] some adrenaline," Andrew said of his experience filming the massacre. "I had been given a taste of how easy it is to kill. After that day I saw more violence: dead bodies in Sadr City, grieving brothers, grieving friends, and again I felt nothing. No emotions. No tears. I knew in my mind that what I was seeing was messed up, but I think that as a defense mechanism I couldn't process it at the time and still function. I was working and living. I had to make decisions."

When he got home, however, the bill came due. "It was almost like I couldn't find a reason to get up in the morning," he explained. "There were no car bombs. Nobody was being killed. It didn't seem like anything important was happening here. I felt such a strong desire to go back to Iraq but at the same time I knew that I needed to deal with what I'd seen and experienced. I knew that there are plenty of reasons to get up in the morning outside of a war zone and I just needed to relearn the job of living day-to-day without violence and death happening around me."

According to a study published in the September 2002 issue of the American Journal of Psychiatry, war reporters are much more likely to experience psychological trauma than journalists who never report on armed conflict. War journalists reported drinking more alcohol and were much more likely to show signs of depression or post-traumatic stress disorder (PTSD). Indeed, the study showed a lifetime rate of PTSD in war journalists of 28.6 percent, and the lifetime rate of depression was 2I.4 percent-rates similar to those of combat veterans. ${ }^{2}$ 
Two months after I returned from Iraq, a friend suggested I go see a psychiatrist in San Francisco's Pacific Heights district. He was a specialist in PTSD, my friend told me, and would be able to tell me if something was wrong with me clinically or if I was just having "issues" that would pass. I found the experience infuriating. The shrink sat back and let me talk for an hour. Afterward, he asked for a check for $\$$ I75 and scheduled an appointment for the next week. I wanted someone who would give me answers to my questions and help me learn ways of coping with my problems on my own. Instead, the psychiatrist promised me a mountain of bills but no guarantee of progress. That was the last thing I wanted, and I never returned.

What turned out to be most helpful to me was the continued practice of journalism. A few months after coming home in 2004, I got a contract to write a book, How America Lost Iraq, where I chronicled how and why Iraqis turned against the U.S. occupation even though they were initially happy about the overthrow of Saddam Hussein. For six months, I spent most of my days listening to the taped interviews I did in Iraq, transcribing them, and reinterpreting them into a coherent narrative that made sense to me.

Veteran crime reporter Bruce Shapiro, who heads the Dart Center for Journalism and Trauma at the University of Washington, told me many reporters find that their journalism can be a kind of therapy. "Our job is to make narratives, to take the fragmented shards of horrifying experiences that would be kicking around disorganized and confused and put them into some kind of shape, and though no one has done a study on this, the broader PTSD literature would suggest that this is a source of resilience," he told me. "I mean, trauma shrinks spend a lot of time with victims getting them to shape the story-to get some control over the experience to have the experience feel a little safer by putting it into narrative memory instead of kind of existential threat memory." 
Another way the book helped was that it gave me the opportunity to process my experiences out loud. When it came out in hardcover in the spring of 2005, I toured the country, speaking at bookstores, churches, and college campuses. I also gave numerous radio and television interviews and was able to explain what happened around me and how I felt about it.

"Storytelling is not just about a narrative, but also about accountability," Shapiro explained. "We do have the ability to lay out lines of accountability for things that have happened, and that serves as a control for some people, and in my experience the experiences that most haunt journalists are most often the ones that we couldn't get adequate attention [for], get out there, get printed, or get to air."

During that book tour, I began to connect with veterans for the first time. They would come up to me at bookstores and ask about my experiences of a particular location where they had been stationed. "What did the Iraqi people there really think?" they asked. "How did they react when approached by a microphone instead of a gun?"

I especially enjoyed talking on overnight shows on AM radio. Soldiers and veterans called in when they couldn't sleep. During one interview, an active duty Marine stationed near Seattle called to talk about his experience shooting an innocent civilian at a checkpoint. At 3:00 A.M. on a talk radio station in Denver, a father called to tell me that his son, who had just returned from Iraq, was now addicted to drugs, as were many of his friends.

In Boston, I spoke on a panel with a former Navy lieutenant who bombed Iraq during the initial invasion. He told me he had become "completely dysfunctional" since returning to the States. He had two young children, "but was in no way able to be a father to them." $\mathrm{He}$ 
told me that since returning to his native Massachusetts in 2004, he had been in and out of the VA's mental facility.

The more stories I heard from American veterans, the closer I felt to them. In a way, I felt like we were alone in this country togetherthe only Americans to see the true horror that is the war in Iraq. I started seeking out vets, to tell their stories on the radio, in wire services, on the Internet, and in newspapers and magazines. I tried my best to make the war personal, to create an undeniable moral urgency inside my listeners and readers so they couldn't ignore the war-or pretend it was something that went on far away and didn't affect them.

That effort culminated in this book, one of the first attempts to systematically explain what Iraq and Afghanistan veterans face when they return home. In its pages, you will read about the difficulties soldiers have reintegrating into civilian life, living with disability and unemployment, dealing with the military bureaucracy, suicide, and homelessness - as well as more upbeat stories about families, communities, and fellow veterans pulling together to help each other.

While each veteran's case is different in its details, a clear pattern emerges overall. American soldiers return from Iraq and Afghanistan different from when they left. They have difficulty relating to their family and friends who never spent time in the war zone. But rather than help them adjust to civilian life, the federal government throws a series of bureaucratic barriers at them that make their problems worse. Injured veterans must battle Pentagon officials for an honorable discharge and then fight with a completely separate Department of Veterans Affairs bureaucracy to get their health care, education, and disability benefits. Oftentimes, that fight is so long and complicated that it pushes a veteran toward withdrawing, using drugs, suicide, or crime. 
But the story doesn't need to go this way. While war is inherently damaging to a person's psyche and physical body, steps can be taken to make the transition from warrior to civilian easier. My hope is that I can show not only problems, but also solutions. As the Vietnam experience indicates, if we don't start addressing these problems now, they'll only get worse with time. 